\title{
Kinetic Isotope Effect on Electron Transfer Rates Across Self-As- sembled Monolayers: A Case for Quantum Effects
}

\author{
Samir Chattopadhyay, * Sabyasachi Bandyopadhyay, * Abhishek Dey* \\ School of Chemical Sciences, Indian Association for the Cultivation of Science, Jadavpur, Kolkata-700032
}

Supporting Information Placeholder

\begin{abstract}
Long range ET across several self-assembled monolayer (SAM) covered Au electrodes is investigated using protonated and deuterated thiols (RSH/RSD). The rate of tunneling is measured using both chronoamperometry and cyclic voltammetry and it shows a prominent KIE. The KIE is $\sim 2$ (normal) for medium chain length thiols where the Tafel plot indicate substantial through space tunneling and is $\sim 0.25$ (inverse) for long chain thiols where the Tafel plot indicate mostly through bond tunneling. These results imply substantial contribution from the classical modes at the Au(H)SR interface, which shift substantially on deuteration of the thiols, to the ET process.
\end{abstract}

\section{Introduction}

Long range electron transfer (ET) has a crucial role in numerous biological processes ranging from photosynthesis to aerobic respiration. ${ }^{1}$ Apart from the energy transfer processes in biology like respiration and photosynthesis, key biological transformations like monooxygenation is rate limited by ET. ${ }^{2}$ In addition to the biological processes, manoeuvring the ET between the electrode and molecular materials is key to molecular electronic devices. ${ }^{3-6}$ Long range ET, its mechanism and factors that intrinsically controls it are of interest to the scientific community. ${ }^{7-10}$ Self-assembled monolayers (SAMs) of organic thiols on coinage metals like Au, Ag, $\mathrm{Cu}$ and $\mathrm{Pt}$ has been evolved to be a convenient model system for investigating ET through molecular closed- packed films as these systems are modular and amenable to chemical modifications. ${ }^{11-12}$ In particular, self-assembled of organothiol monolayers on $\mathrm{Au}$ electrodes are extensively used due to the thermodynamic stability of $\mathrm{Au}-\mathrm{S}$ bond and the inertness of Au towards oxidation. ${ }^{13}$ The kinetics of ET between the electrode and a redox active moiety through SAM can be monitored by electrochemical, photochemical and temperature jump techniques. ${ }^{4,11,14-15}$ Among various electrochemical methods available, cyclic voltammetry and chronoamperometry have been widely used to study the ET kinetics across the SAM. ${ }^{1,16-17}$

The structure of Au-thiol interfaces in thiol coated nanoparticles (3D SAMs) and thiol SAM on Au surfaces (2D SAMs) are different. ${ }^{18-24}$ High resolution crystal structure and the quantification of $\mathrm{H}_{2}$ gas produced during SAM formation clearly indicates that the Au-thiol interface in SAM coated nanoparticles contains thiolates. ${ }^{25-30}$ Recently, is has been shown that the valance state of Authiol interface contains $\mathrm{Au}(0)$-thiyl with $\mathrm{Au}-\mathrm{d}$ orbital dominated interactions in contrast to the Au-s orbital interactions present in the $\mathrm{Au}$ (I)-thiolate compounds. ${ }^{31-32}$ In general ET across Au-SAM can be viewed as non-adiabatic with a sharp decrease in electron tunnelling probability with increasing the length of the spacer between the electrode (donor) and the redox active moiety (acceptor) i.e., the chain length of the SAM. ${ }^{33}$ Ulstrup and co-workers have determined the interfacial ET from Au (111) to Azurin attached by alkanethiol of differing chain length. ${ }^{34}$ They have established that the ET rate constant remains virtually independent up to 9 methylene unit containing linkers and then falls off exponentially with a decay coefficient for electron tunnelling, $B=1.03 \pm 0.02$ per methylene unit for longer alkyl thiol spacer and this value of $\beta$ is very close to the value estimated from cyclic voltammetry, indirect laser induced temperature jump method, electrochemical impedance measurement and potential modulated electro reflectance techniques for redox active moiety attached to thiol SAM on Au. ${ }^{10,17}$, ${ }^{35-39}$ Several groups have reported ET control of chemical reactions by controlling the chain length of the SAM. Collman and co-workers have shown that the selectivity of $\mathrm{O}_{2}$ reduction by a model complex of cytochrome c oxidase $(\mathrm{CcO})$ chemically attached to thiol modified $\mathrm{Au}$ electrode follows same kinetics as found in-vivo in which selectivity depends on the rate of ET to the active site. ${ }^{40}$ In the case of mononuclear Fe-porphyrins, where additional redoxcentres are absent, the selectivity of electrochemical $\mathrm{O}_{2}$ reduction is limited by the rate of ET from the electrode to the active site. ${ }^{41}$ Most recently reactivity of iron-porphyrins on SAM covered Au could be switched between $\mathrm{O}_{2}$ reduction to monooxygenation by controlling the ET rate. ${ }^{42}$ Thus control of ET is evolving as a tool for reaction engineering.

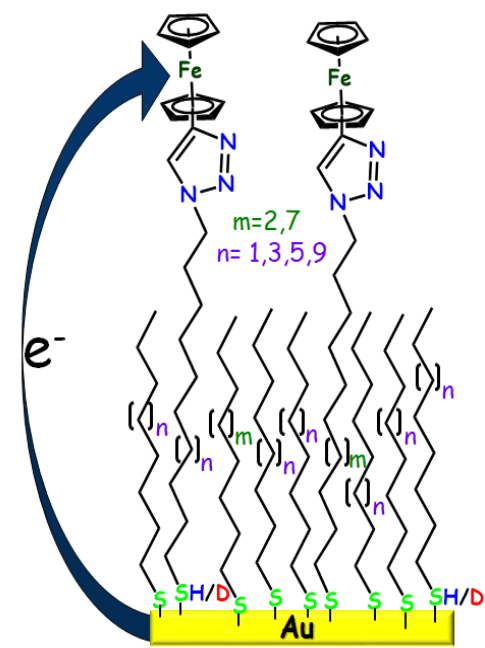

Scheme 1: Schematic representation of ET from Au electrode to ethynyl ferrocene $(\mathrm{EtnFc})$ covalently attached to the mixed SAM of different chain length. 
Recently, from experimental findings and theoretical modelling, it has been established that for short-chain alkyl thiol, namely methanethiol and propane thiol, SAM formation on Au surfaces take place via non-dissociative pathway. ${ }^{18-20,43-44}$ Simultaneously, it has been reported that SAM formed from solution deposition methods on gold and silver surfaces consists of both thiol and thiolate with ratios varying between 1:3 to 1:2.5 (Scheme 1). A $\sim 400 \mathrm{~cm}^{-1}$ shift in the $v_{\mathrm{S}-\mathrm{H}}$ mode and $>15 \mathrm{~cm}^{-1}$ shift in $v_{\mathrm{CS}}$ mode was observed upon deuteration of the thiol proton in the surface enhanced Raman spectroscopy (SERS). X-ray photoelectron spectroscopy data indicate the presence of both thiol and thiolates in these SAM-modified $\mathrm{Au} / \mathrm{Ag}$ surfaces. ${ }^{45-46}$ The same techniques show the lack of protonated thiols on $\mathrm{Au} / \mathrm{Ag}$ nanoparticles.

In this manuscript, the interfacial ET rate from Au electrode to the ethynyl ferrocene $(\mathrm{EtnFc})$ covalently attached through alkyl thiol SAM of different chain length (Scheme 1) is determined by electrochemical techniques like cyclic voltammetry (CV) using Laviron's formalism $\left(\mathrm{k}^{0}\right)$ and chronoamperometry $(\mathrm{CA})\left(\mathrm{k}_{\mathrm{app}}\right)$ of both in their protonated (R-SH) and deuterated (R-SD) variety. The data clearly show the presence of a kinetic isotope effect (KIE) on the measured tunnelling rates which varies with the chain length of the SAM.

\section{Results}

Cyclic voltammograms of EtnFc attached on the $\mathrm{N}_{3} \mathrm{C}_{11} \mathrm{SH}-\mathrm{C}_{8} \mathrm{SH}$ self-assembled monolayers (SAMs) modified Au electrode shows an $\mathrm{E}_{1 / 2}$ at $300 \mathrm{mV}$ at $1 \mathrm{Vps}$ scan rate in $\mathrm{pH} 7$ phosphate buffer at room temperature (Fig. S1A). The ET rate from the Au electrode to the covalently bound EtnFc across the SAM has been determined using chronoamperometry. Chronoamperometry is a very useful tool for the determination of apparent ET rate $\left(\mathrm{k}_{\mathrm{app}}\right)$ from an electrode to a redox active species bound to various SAMs modified electrode. In CA experiments, the faradaic current decays according to the following exponential relationship.

$$
\mathrm{i}=\mathrm{k}_{\mathrm{app}} \mathrm{Q} \exp \left(-\mathrm{k}_{\mathrm{app}} \mathrm{t}\right)
$$

where $\mathrm{Q}$ denotes the amount of charge passed during this redox transformation. The CA current decay comprises two types of processes, one for the overall capacitive current decay and the other is due to the faradaic current decay of the attached redox active moiety. The charging current decays very much faster than the faradaic current. ${ }^{47}$ This helps to determine the $\mathrm{k}_{\text {app }}$ of ET from the electrode to the attached redox active species by simply choosing the appropriate time scale of decay. The plot of $\operatorname{Ln}(\mathrm{i}) v s$. time is linear and its slope yields the value of $\mathrm{k}_{\mathrm{app}}{ }^{48}$

Chronoamperograms of $\mathrm{N}_{3} \mathrm{C}_{11} \mathrm{SH}-\mathrm{C}_{8} \mathrm{SH}$ SAM-modified $\mathrm{Au}$ electrodes demonstrate a complete decay of charging currents within $0.2 \mathrm{~ms}$ time scale (Fig. S2A) whereas the faradaic currents decay completely at $7.5 \mathrm{~ms}$ when EtnFc covalently bound to it (Fig. S3A). The ET rate from the modified Au electrode to the EtnFc in $\mathrm{pH} 7$ phosphate buffer is determined from the slope of the corresponding semilogarithmic plot of $\operatorname{Ln}(\mathrm{i}) v \mathrm{~s}$. time and is found to be $1030 \mathrm{~s}^{-1}$ which reduced to $575 \mathrm{~s}^{-1}$ when EtnFc bound $\mathrm{N}_{3} \mathrm{C}_{11}$ SD-C $\mathrm{C}_{8}$ SD SAMmodified Au electrode in presence of pD7 phosphate buffer(Fig. $1 \mathrm{~A}$ and $1 \mathrm{~B})$. Note that, the proton at the interface can be exchanged slowly and reversibly with deuterium in the bulk solvent and viceversa (Fig. S7). The $\Delta$ Ep gradually changes from that of the deuterated SAM to that of the protonated SAM i.e. $\triangle$ Ep of the deuterated $\mathrm{SAM}$ in $\mathrm{D}_{2} \mathrm{O}$ is identical to $\triangle \mathrm{Ep}$ of deuterated $\mathrm{SAM}$ in $\mathrm{H}_{2} \mathrm{O}$ solvent before it slowly exchanged. The composition of $\mathrm{N}_{3} \mathrm{C}_{11} \mathrm{SD}$ $\mathrm{C}_{8} \mathrm{SD}$ SAM-modified Au electrode remains conserved throughout the entire timescale of experiments (Fig. S8A). In-situ SERS data of the electrode before, after attachment of EtnFc shows no changes in the SERS data. Similarly, there are no changes in the SERS data when potential is applied in aqueous medium. (Fig. S12) XPS data shows similar distribution of HSR/RS in both of the protonated and deuterated SAM. (Fig. S13) Thus, the SERS data together with the XPS data confirms the fact that the environment of the Au-SAM interface does not change upon deuteration. Chronoamperometry is also performed in organic medium (DCM having tetra butyl ammonium perchlorate, TBAP as electrolyte) and it is found that the interfacial ET rate decreases upon deuteration as well. In the case of protonated variant, the ET rate from the SAM modified Au electrode is determined to be $34 \mathrm{~s}^{-1}$ which reduces to $16.75 \mathrm{~s}^{-1}$ when the ET has been done across the deuterated SAM. (Fig.1C and 1D) The slow $\mathrm{k}_{\text {app }}$ in an organic solvent is consistent with their larger solvent reorganization relative to water. Kinetic isotope effect (KIE) for this construct is found to be 1.79 in aqueous medium and 2.02 for the same in organic medium.
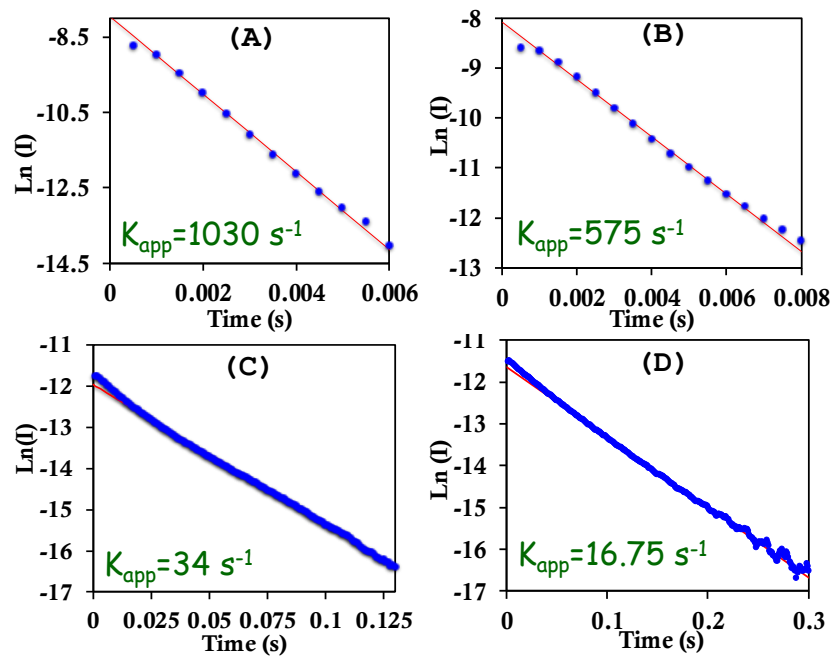

Fig 1: Chronoamperometric semilogarithmic plot for of $\operatorname{Ln}(i)$ vs. time with their regression fittings for EtnFc chemically bound to $\mathrm{Au}$ electrodes modified with $\mathrm{N}_{3} \mathrm{C}_{11} \mathrm{SH}-\mathrm{C}_{8} \mathrm{SH}$ SAM, in (A) $\mathrm{pH} 7$ phosphate buffer (C) DCM-TBAP and $\mathrm{N}_{3} \mathrm{C}_{11} \mathrm{SD}-\mathrm{C}_{8} \mathrm{SD}$ SAM in (B) pD7 phosphate buffer (D) DCM-TBAP. Here, the overpotential is $10 \mathrm{mV}$.
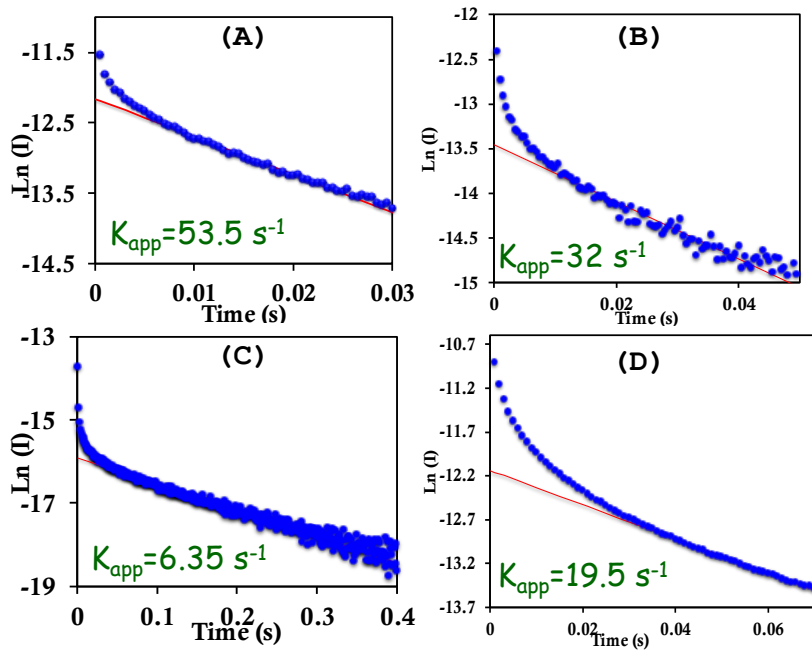

Fig 2: Chronoamperometric semilogarithmic plot for of $\operatorname{Ln}(\mathrm{i})$ vs. time with their regression fittings for EtnFc chemically bound to $\mathrm{Au}$ electrodes modified with (A) $\mathrm{N}_{3} \mathrm{C}_{16} \mathrm{SH}-\mathrm{C}_{12} \mathrm{SH}$, (B) $\mathrm{N}_{3} \mathrm{C}_{16} \mathrm{SD}$ $\mathrm{C}_{12} \mathrm{SD}$, (C) $\mathrm{N}_{3} \mathrm{C}_{16} \mathrm{SH}-\mathrm{C}_{16} \mathrm{SH}$ and (D) $\mathrm{N}_{3} \mathrm{C}_{16} \mathrm{SD}-\mathrm{C}_{16} \mathrm{SD} \mathrm{SAM}$, in $\mathrm{pH} 7 / \mathrm{pD} 7$ phosphate buffer. Here, the overpotential is $10 \mathrm{mV}$.

These initial data on KIE on ET for $\mathrm{N}_{3} \mathrm{C}_{11} \mathrm{SH} / \mathrm{D}-\mathrm{C}_{8} \mathrm{SH} / \mathrm{D}$ SAM modified Au electrode with EtnFc bound to it, is extended to higher chain length mixed SAM $\left(\mathrm{N}_{3} \mathrm{C}_{16} \mathrm{SH} / \mathrm{D}-\mathrm{C}_{12} \mathrm{SH} / \mathrm{D}\right.$ and $\mathrm{N}_{3} \mathrm{C}_{16} \mathrm{SH} / \mathrm{D}-$ 
$\left.\mathrm{C}_{16} \mathrm{SH} / \mathrm{D}\right)$ modified $\mathrm{Au}$ electrode. The cyclic voltammograms of EtnFc attached on the $\mathrm{N}_{3} \mathrm{C}_{16} \mathrm{SH}-\mathrm{C}_{12} \mathrm{SH}$ and $\mathrm{N}_{3} \mathrm{C}_{16} \mathrm{SH}-\mathrm{C}_{16} \mathrm{SH}$ SAMs modified $\mathrm{Au}$ electrode are measured at $1 \mathrm{Vps}$ scan rate in $\mathrm{pH} 7$ phosphate buffer at room temperature (Fig. S1). A reversible CV is obtained in all these cases. The potential of the $\mathrm{Fc} / \mathrm{Fc}^{+}$varies slightly with the chain length of the thiol due to changes in the micro solvation environment of the $\mathrm{Fc}^{+}{ }^{49}$ The separation between the anodic $\left(\mathrm{E}_{\mathrm{a}}\right)$ and cathodic processes $\left(\mathrm{E}_{\mathrm{c}}\right)$ indicates different tunneling rates across thiols of different chain length. These rates of ET are determined using both chronoamperometry as well as using Laviron's treatment. These two SAMs reveal the same time scale of charging current decay (Fig. S2) as the $\mathrm{N}_{3} \mathrm{C}_{11} \mathrm{SH}-\mathrm{C}_{8} \mathrm{SHSAM}$ but their faradaic current decays completely at $250 \mathrm{~ms}$ and $500 \mathrm{~ms}$ for $\mathrm{N}_{3} \mathrm{C}_{16} \mathrm{SH}-\mathrm{C}_{12} \mathrm{SH}$ and $\mathrm{N}_{3} \mathrm{C}_{16} \mathrm{SH}-\mathrm{C}_{16} \mathrm{SH}$ respectively (Fig. S3). In comparison to the protonated variants the deuterated SAM shows a complete decay of faradaic current at $300 \mathrm{~ms}$ and $100 \mathrm{~ms}$ for $\mathrm{N}_{3} \mathrm{C}_{16} \mathrm{SD}-\mathrm{C}_{12} \mathrm{SD}$ and $\mathrm{N}_{3} \mathrm{C}_{16} \mathrm{SD}-\mathrm{C}_{16} \mathrm{SD}$ respectively (Fig. S5) and corresponding charging current decays have been shown in Fig. S4. The apparent ET rate, kapp from the modified Au electrode to the bound EtnFc moiety is determined from the slope of the $\mathrm{Ln}(\mathrm{i}) \mathrm{vs}$. time plot and is found to be $53.5 \mathrm{~s}^{-1}$ for $\mathrm{N}_{3} \mathrm{C}_{16} \mathrm{SH}-\mathrm{C}_{12} \mathrm{SH}$ SAM which upon deuteration decreases to $32 \mathrm{~s}^{-1}$. (Fig. 2A \& 2B) In case of $\mathrm{N}_{3} \mathrm{C}_{16} \mathrm{SH}-\mathrm{C}_{16} \mathrm{SH}$ SAM, a kapp value of $7.5 \mathrm{~s}^{-1}$ is determined from the slope but surprisingly upon deuteration the apparent ET rate, $\mathrm{k}_{\text {app }}$ increases to $19.5 \mathrm{~s}^{-1}$. (Fig. 2C \& 2D) These values of kapp for protonated variants are in close agreement with the previous reports on the systems. ${ }^{50}$ (Table 1) The $\mathrm{k}_{\text {app }}$ of ET from the $\mathrm{N}_{3} \mathrm{C}_{11} \mathrm{SH}-$ $\mathrm{C}_{10} \mathrm{SH}$ is estimated to be $540 \mathrm{~s}^{-1}$. (Fig. S6, Table 1) Thus, the kapp reduces from $1030 \mathrm{~s}^{-1}$ to $540 \mathrm{~s}^{-1}$ and $7.5 \mathrm{~s}^{-1}$ as the chain length is increased from $\mathrm{C}_{8} \mathrm{SH}$ to $\mathrm{C}_{10} \mathrm{SH}$ and $\mathrm{C}_{16} \mathrm{SH}$ reproducing previous data on similar systems. ${ }^{50}$ The $\mathrm{k}_{\mathrm{ET}}$ shows a normal H/D isotope effect in the case of $\mathrm{N}_{3} \mathrm{C}_{11} \mathrm{SH}-\mathrm{C}_{8} \mathrm{SH} / \mathrm{N}_{3} \mathrm{C}_{16} \mathrm{SH}-\mathrm{C}_{12} \mathrm{SH}$ but is inverse in the case of $\mathrm{N}_{3} \mathrm{C}_{16} \mathrm{SH}-\mathrm{C}_{16} \mathrm{SH}$.

The heterogeneous ET rate constant at zero overpotential (the standard rate constant, $\mathrm{k}^{0}$ ) from the electrode to a redox active species either chemically bound or adsorbed onto it can also be determined by Laviron's approach. ${ }^{51}$ This method is mainly based on Butler- Volmer approach with the separation between cathodic and anodic peak potential $\left(\Delta \mathrm{E}_{\mathrm{p}}\right)$ at different scan rates $(v)$ as the only experimental requirement. Transfer coefficient $(\alpha)$ is an important parameter used in this approach which indicates the symmetry of the energy barrier during the redox process. The value of $\alpha$ is 0.5 for the ideal case but may vary from $0.5 .{ }^{52}$ Transfer coefficient $\alpha$ can be determined from the slope of the plot of cathodic $\left(\mathrm{E}_{\mathrm{pc}}\right)$ and anodic $\left(\mathrm{E}_{\mathrm{pa}}\right)$ peak potential vs. $\ln (\mathrm{v})$. At higher scan rates where $\Delta \mathrm{E}_{\mathrm{p}}>100 \mathrm{mV}$, the intercept of the $\Delta \mathrm{E}_{\mathrm{p}} v s . \log (v)$ plot and the determined $\alpha$ value yields the standard ET rate $\left(\mathrm{k}^{0}\right) .{ }^{52}$ Modified electrodes with EtnFc clicked on $\mathrm{N}_{3} \mathrm{C}_{11} \mathrm{SH} / \mathrm{D}-\mathrm{C}_{8} \mathrm{SH} / \mathrm{D}$ and $\mathrm{N}_{3} \mathrm{C}_{11} \mathrm{SH}-\mathrm{C}_{10} \mathrm{SH} \mathrm{SAM}$ show a high rate of ET and the prerequisite for applying Laviron's approach $\left(\Delta \mathrm{E}_{\mathrm{p}}>100 \mathrm{mV}\right)$ is only observed for the very high scan rates. Alternatively, $\mathrm{EtnFc}$ bound $\mathrm{N}_{3} \mathrm{C}_{16} \mathrm{SH} / \mathrm{D}-\mathrm{C}_{12} \mathrm{SD}$ and $\mathrm{N}_{3} \mathrm{C}_{16} \mathrm{SH} / \mathrm{D}-\mathrm{C}_{16} \mathrm{SH} / \mathrm{D}$ modified $\mathrm{Au}$ electrodes show much larger $\Delta \mathrm{E}_{\mathrm{p}}$ at slow scan rates and are amenable to Laviron's treatment. The scan rate dependent cyclic voltammograms of EtnFc bound to $\mathrm{N}_{3} \mathrm{C}_{16} \mathrm{SH}-\mathrm{C}_{12} \mathrm{SH}$ and $\mathrm{N}_{3} \mathrm{C}_{16} \mathrm{SH}-\mathrm{C}_{16} \mathrm{SH}$ SAM-modified $\mathrm{Au}$ electrodes are done in $\mathrm{pH} 7$ phosphate buffer (Fig. S9). Using the slope of the $E_{p}$ vs. ln (v) plot, the value of $\alpha$ has been calculated as 0.49 and 0.50 for $\mathrm{N}_{3} \mathrm{C}_{16} \mathrm{SH}-\mathrm{C}_{12} \mathrm{SH}$ and $\mathrm{N}_{3} \mathrm{C}_{16} \mathrm{SH}-\mathrm{C}_{16} \mathrm{SH}$ modified $\mathrm{Au}$ electrodes (Fig. 3A and C), respectively. The difference in cathodic and anodic peak potential $\left(\Delta \mathrm{E}_{\mathrm{p}}\right)$ for the $\mathrm{N}_{3} \mathrm{C}_{16} \mathrm{SH}-\mathrm{C}_{12} \mathrm{SH}$ and $\mathrm{N}_{3} \mathrm{C}_{16} \mathrm{SH}-\mathrm{C}_{16} \mathrm{SH}$ modified Au electrodes, against $\log (v)$ is linear. (Fig. 3B and D) With the intercept and the $\alpha$, the value of $\mathrm{k}^{0}$ estimated to be $17.62 \mathrm{~s}^{-1}$ and $2.30 \mathrm{~s}^{-1}$, for $\mathrm{N}_{3} \mathrm{C}_{16} \mathrm{SH}-\mathrm{C}_{12} \mathrm{SH}$ and $\mathrm{N}_{3} \mathrm{C}_{16} \mathrm{SH}-\mathrm{C}_{16} \mathrm{SH}$ modified Au electrodes, respectively.
The cyclic voltammograms of EtnFc attached to the $\mathrm{N}_{3} \mathrm{C}_{16} \mathrm{SD}$ $\mathrm{C}_{12} \mathrm{SD}$ and $\mathrm{N}_{3} \mathrm{C}_{16} \mathrm{SD}-\mathrm{C}_{16} \mathrm{SD}$ modified $\mathrm{Au}$ electrodes are obtained with varying scan rates (Fig. S10). The $\alpha$ values obtained from the slope of the $\mathrm{E}_{\mathrm{p}} v s$. $\ln (v)$ plot of $\mathrm{N}_{3} \mathrm{C}_{16} \mathrm{SD}-\mathrm{C}_{12} \mathrm{SD}$ (Fig. 4A) and $\mathrm{N}_{3} \mathrm{C}_{16} \mathrm{SD}-\mathrm{C}_{16} \mathrm{SD}$ (Fig. 4C) are 0.45 and 0.64 , respectively. These calculated $\alpha$ values along with the intercepts from the $\Delta \mathrm{E}_{\mathrm{p}} v s . \log$ (v) (Fig. 4B and D) yields standard rate of ET $\left(\mathrm{k}^{0}\right)$ of $10.9 \mathrm{~s}^{-1}$ and $9.2 \mathrm{~s}^{-1}$, for $\mathrm{N}_{3} \mathrm{C}_{16} \mathrm{SD}-\mathrm{C}_{12} \mathrm{SD}$ and $\mathrm{N}_{3} \mathrm{C}_{16} \mathrm{SD}-\mathrm{C}_{16} \mathrm{SD}$ modified Au electrode, respectively. Note that, there is no H/D exchange happens in the case of $\mathrm{N}_{3} \mathrm{C}_{16} \mathrm{SD}-\mathrm{C}_{12} \mathrm{SD}$ and $\mathrm{N}_{3} \mathrm{C}_{16} \mathrm{SD}-\mathrm{C}_{16} \mathrm{SD}$ SAM during the entire timescale of experiments (Fig. S8B and 8C).
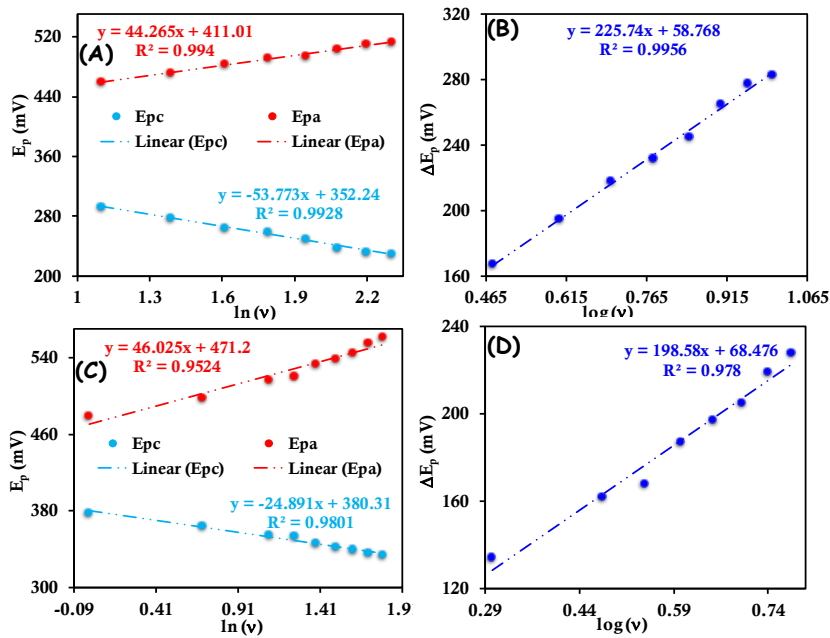

Fig 3: Peak potential $\left(\mathrm{E}_{\mathrm{p}}\right) v s$. $\ln (v)$ plot for EtnFc attached to the (A) $\mathrm{N}_{3} \mathrm{C}_{16} \mathrm{SH}-\mathrm{C}_{12} \mathrm{SH}$ SAM and (C) $\mathrm{N}_{3} \mathrm{C}_{16} \mathrm{SH}-\mathrm{C}_{16} \mathrm{SH}$ SAM modified Au electrode. $\mathrm{B}$ and $\mathrm{D}$ represent corresponding $\Delta \mathrm{E}_{\mathrm{p}} \mathrm{vs} . \log (\mathrm{v})$ plot for the same respectively.
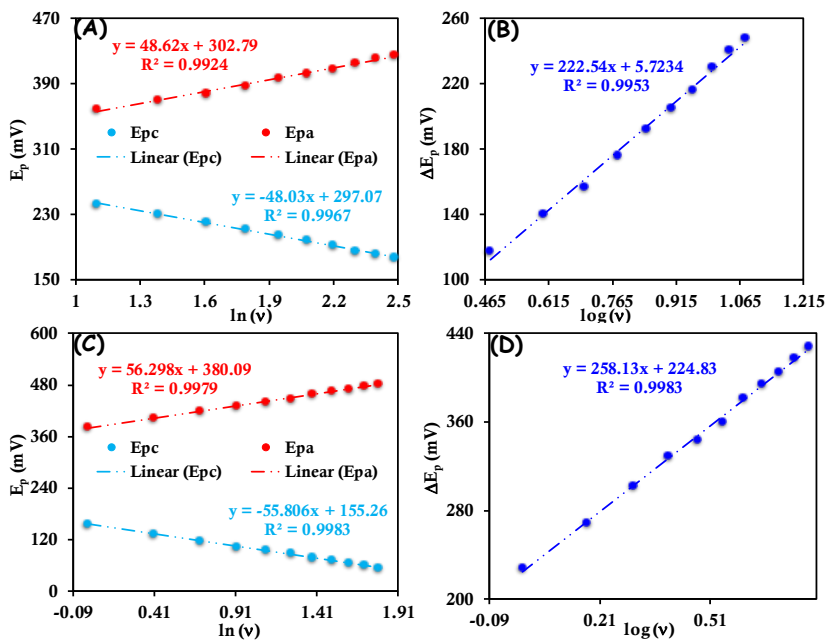

Fig 4: Peak potential $\left(\mathrm{E}_{\mathrm{p}}\right)$ vs. $\ln (v)$ plot for $\mathrm{EtnFc}$ attached to the deuterated $\mathrm{N}_{3} \mathrm{C}_{16} \mathrm{SD}-\mathrm{C}_{12} \mathrm{SD}$ mixed self-assembled monolayer(A) and $\mathrm{N}_{3} \mathrm{C}_{16} \mathrm{SD}-\mathrm{C}_{16} \mathrm{SD}$ mixed self-assembled monolayer $(\mathrm{C})$. $\mathrm{B}$ and $D$ represent corresponding $\Delta \mathrm{E}_{\mathrm{p}} \mathrm{vs} . \log (\mathrm{v})$ plot for the same respectively.

A comparison of the apparent rate constant $\left(\mathrm{k}_{\text {app }}\right)$ and standard ET rate $\left(\mathrm{k}^{0}\right)$ from the $\mathrm{Au}$ electrode to the $\mathrm{EtnFc}$ bound to different protonated and deuterated mixed self-assembled monolayers is presented (Table 1). The KIE obtained from the standard ET rate $\left(\mathrm{k}^{0}\right)$ is found to be 1.61 for EtnFc attached to $\mathrm{N}_{3} \mathrm{C}_{16} \mathrm{SH} / \mathrm{D}-\mathrm{C}_{12} \mathrm{SH} / \mathrm{D}$ modified $\mathrm{Au}$ electrode. Interestingly in the case of $\mathrm{N}_{3} \mathrm{C}_{16} \mathrm{SH} / \mathrm{D}$ $\mathrm{C}_{16} \mathrm{SH} / \mathrm{D}$ mixed SAM an inverse KIE is detected with a value of 0.25 . To further confirm the fact that tunneling is faster in 
deuterated SAM, H/D exchange is performed in-situ (Fig. S7). With increasing, the time of incubation of the EtnFc bound deuterated $\mathrm{SAM}$ in $\mathrm{H}_{2} \mathrm{O}$, the $\Delta \mathrm{Ep}$ value increases indicating a decrease in ET rate upon deuterium exchange with proton. Note that, any defect in the SAM upon incubation would have made the ET faster not slower. The KIE for the ET from the modified Au electrode to the EtnFc moiety attached to it is also calculated from the respective $k_{\text {app }}$ values for these two different mixed SAMs. The KIE value is found to be dependent on the applied overpotential and in contrast to the $\mathrm{N}_{3} \mathrm{C}_{11} \mathrm{SH} / \mathrm{D}-\mathrm{C}_{8} \mathrm{SH} / \mathrm{D}$ mixed SAM, the $\mathrm{N}_{3} \mathrm{C}_{16} \mathrm{SH} / \mathrm{D}$ $\mathrm{C}_{12} \mathrm{SH} / \mathrm{D}$ mixed SAM, show opposite trends in change of KIE with overpotential. (Fig. S11) With increasing overpotential, the KIE gets more prominent with lowest KIE value obtained at lowest overpotential.

Table 1: Comparison of $k_{\text {app }}$ and $k^{0}$ of ET for EtnFc bound different mixed self-assembled monolayers on Au with both in protonated (blue) and deuterated (red) version. Reported values of the same (whenever applicable) mentioned in \{\} with italics style.

\begin{tabular}{|c|c|c|c|c|}
\hline SAMs & $\mathbf{k}_{\text {app }}\left(\mathrm{s}^{-1}\right)$ & $\begin{array}{l}\text { KIE } \\
\text { (from } \\
\mathbf{k}_{\text {app }} \text { ) }\end{array}$ & $k^{0}\left(s^{-1}\right)$ & $\begin{array}{l}\text { KIE } \\
\text { (from } \\
\mathbf{k}^{\mathbf{0}} \text { ) }\end{array}$ \\
\hline $\begin{array}{l}\mathrm{N}_{3} \mathrm{C}_{11} \mathrm{SH}(\mathrm{D})- \\
\mathrm{C}_{8} \mathrm{SH}(\mathrm{D})\end{array}$ & $\begin{array}{l}1030 \pm 11 \\
(575 \pm 8)\end{array}$ & 1.79 & $\begin{array}{l}-- \\
-)\end{array}$ & -- \\
\hline $\begin{array}{l}\mathrm{N}_{3} \mathrm{C}_{11} \mathrm{SH}(\mathrm{D})- \\
\mathrm{C}_{10} \mathrm{SH}(\mathrm{D})\end{array}$ & $\begin{array}{l}540 \pm 5 \\
\{500 \pm 2\}^{50}\end{array}$ & & $\begin{array}{l}-- \\
-)\end{array}$ & -- \\
\hline $\begin{array}{l}\mathrm{N}_{3} \mathrm{C}_{16} \mathrm{SH}(\mathrm{D})- \\
\mathrm{C}_{12} \mathrm{SH}(\mathrm{D})\end{array}$ & $\begin{array}{l}53.5 \pm 6 \\
(32 \pm 2) \\
\{20 \pm 6\}^{50}\end{array}$ & 1.67 & $\begin{array}{l}17.6 \pm 0.8 \\
(10.9 \pm 0.5)\end{array}$ & 1.61 \\
\hline $\begin{array}{l}\mathrm{N}_{3} \mathrm{C}_{16} \mathrm{SH}(\mathrm{D})- \\
\mathrm{C}_{16} \mathrm{SH}(\mathrm{D})\end{array}$ & $\begin{array}{l}7.5 \pm 0.3 \\
(19.5 \pm 1) \\
\{2.2 \pm 0.2\}^{50}\end{array}$ & 0.38 & $\begin{array}{l}2.3 \pm 0.2 \\
(9.2 \pm 0.5) \\
\{1.3\}^{47}\end{array}$ & 0.25 \\
\hline
\end{tabular}

While both of the $\mathrm{N}_{3} \mathrm{C}_{11} \mathrm{SH} / \mathrm{D}-\mathrm{C}_{8} \mathrm{SH} / \mathrm{D}$ and $\mathrm{N}_{3} \mathrm{C}_{16} \mathrm{SH} / \mathrm{D}-\mathrm{C}_{12} \mathrm{SH} / \mathrm{D}$ SAM exhibit normal isotope effects on $\mathrm{k}_{\mathrm{ET}}, \mathrm{N}_{3} \mathrm{C}_{16} \mathrm{SH} / \mathrm{D}-\mathrm{C}_{16} \mathrm{SH} / \mathrm{D}$ SAM shows an inverse KIE (Fig. S11). The ET rate determined in both potential step chronoamperometry and Laviron's treatment shows that the deuterated SAM have a higher rate of ET than the corresponding protonated one which in contrast to the other constructs. The KIE determined from the ET rates obtained from Laviron's formalism (zero overpotential) and from chronoamperometry at lowest overpotential applied, are very close to each other (Table 1). Overall both kapp (CA) and $\mathrm{k}^{0}$ (Laviron's methods) established a substantial difference in rates depending on the isotopic substitution of the thiols constituting the SAMs. In particular, the KIE can be both normal, as is the case of $\mathrm{N}_{3} \mathrm{C}_{11} \mathrm{SH} / \mathrm{D}-\mathrm{C}_{8} \mathrm{SH} / \mathrm{D}$ and $\mathrm{N}_{3} \mathrm{C}_{16} \mathrm{SH} / \mathrm{D}-\mathrm{C}_{12} \mathrm{SH} / \mathrm{D}$ SAMs or inverse as in the case of $\mathrm{N}_{3} \mathrm{C}_{16} \mathrm{SH} / \mathrm{D}-\mathrm{C}_{16} \mathrm{SH} / \mathrm{D}$ SAM as determined using two different electrochemical techniques.

The Tafel plots of the alkyl thiol SAM modified Au electrode shows different types of signatures depending upon the chain length of the SAM. In case of short chain mixed SAM, $\left(\mathrm{N}_{3} \mathrm{C}_{11} \mathrm{SH} / \mathrm{D}-\mathrm{C}_{8} \mathrm{SH} / \mathrm{D}\right)$ the Tafel plot shows curved nature with asymmetry which indicates that through space tunneling mechanism is operational during the interfacial $\mathrm{ET}^{53}$ and as the chain length increases, the curved and asymmetrical nature of the Tafel plot vanishes reflecting the fact that with the increase in chain length of the SAM, the nature of ET changes from through space to through bond tunneling. The KIE on ET shows a maximum value of $\sim 2$ for the $\mathrm{N}_{3} \mathrm{C}_{11} \mathrm{SH} / \mathrm{D}-\mathrm{C}_{8} \mathrm{SH} / \mathrm{D}$ SAM modified $\mathrm{Au}$ electrode (through space tunneling) which decreases to 0.38 for $\mathrm{N}_{3} \mathrm{C}_{16} \mathrm{SH} / \mathrm{D}$ $\mathrm{C}_{16} \mathrm{SH} / \mathrm{D}$ SAM modified Au electrode (through bond tunneling) with an in between value of KIE of 1.67 for the $\mathrm{N}_{3} \mathrm{C}_{16} \mathrm{SH} / \mathrm{D}$ $\mathrm{C}_{12} \mathrm{SH} / \mathrm{D} \mathrm{SAM}$ modified Au electrode (a mixture of through space and through bond tunneling).

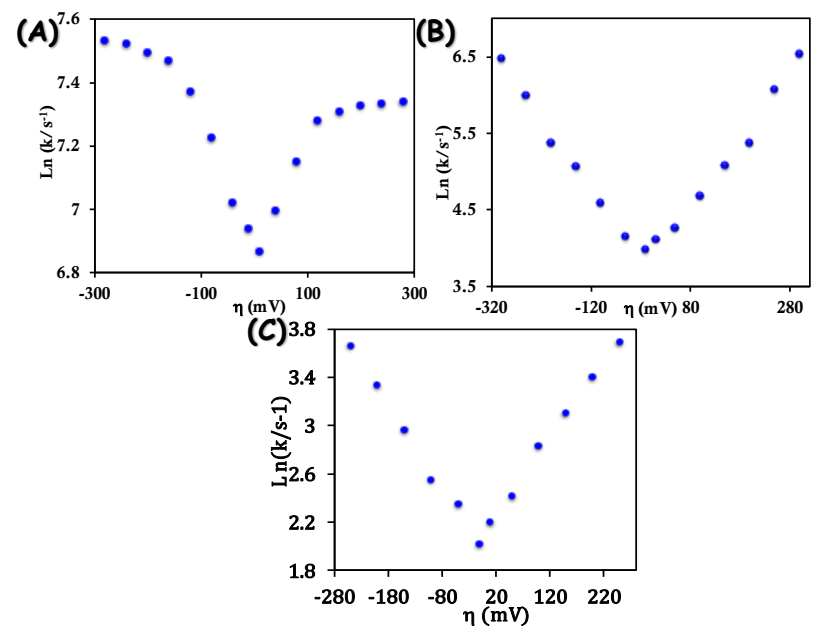

Fig 5: Tafel plot for (A) $\mathrm{N}_{3} \mathrm{C}_{11} \mathrm{SH}-\mathrm{C}_{8} \mathrm{SH}$ (B) $\mathrm{N}_{3} \mathrm{C}_{16} \mathrm{SH}-\mathrm{C}_{12} \mathrm{SH}$ and (C) $\mathrm{N}_{3} \mathrm{C}_{16} \mathrm{SH}-\mathrm{C}_{16} \mathrm{SH} \mathrm{SAM}-$ modified $\mathrm{Au}$ electrodes. The corresponding rates are calculated using chronoamperometric techniques.

\section{Discussion}

Two key findings are reported here: (1) there is H/D KIE on interfacial ET across the thiol SAM covered Au electrodes. (2) the KIE changes from normal in the case of short chain thiol where there is substantial through space tunneling is operational, to inverse in long chain thiol SAM covered Au electrode where there is mostly through bond tunneling operates during ET.

In the recent past, we and others have shown that a fraction of thiols comprising the SAMs on flat electrodes is protonated. ${ }^{18-20,45}$ The $\mathrm{S}-\mathrm{H}$ vibration is observed at $2155 \mathrm{~cm}^{-1}$ shifts to $1740 \mathrm{~cm}^{-1}$ and the $v_{\mathrm{cs}}$ vibration shifts from $649 \mathrm{~cm}^{-1}$ to $632 \mathrm{~cm}^{-1}$ upon deuteration of the thiols. ${ }^{45}$ The results presented using multiple techniques on a set of SAM-Au constructs indicates an H/D isotope effect originate from the thiols present at the interface. For the $\mathrm{N}_{3} \mathrm{C}_{11} \mathrm{SH} / \mathrm{D}$ $\mathrm{C}_{8} \mathrm{SH} / \mathrm{D}$ SAM where there is substantial through space tunneling, the KIE is normal. The KIE on $\mathrm{kET}_{\mathrm{ET}}$ shows almost similar values determined from both of the electrochemical techniques. In the case of $\mathrm{N}_{3} \mathrm{C}_{16} \mathrm{SH}$ (D)- $\mathrm{C}_{12} \mathrm{SH}$ (D) SAM KIE obtained from chronoamperometry is 1.67 whereas the same determined from $\mathrm{CV}$ is 1.61 . Again, a reverse KIE is obtained with a value of 0.38 from $k_{a p p}$ and 0.25 from $\mathrm{k}^{0}$ in the case of $\mathrm{N}_{3} \mathrm{C}_{16} \mathrm{SH}(\mathrm{D})-\mathrm{C}_{16} \mathrm{SH}(\mathrm{D}) \mathrm{SAM}$ modified $\mathrm{Au}$ electrode where the tunneling mechanism is operating through bond.

The results obtained here necessitate inclusion of contributions from vibrational modes in models of non-adiabatic long-range ET tunneling. In such cases, the rate of ET depends on several factors which includes the effect of displacement of potential energy surfaces of the oxidized and the reduced partner during ET, and the effect of anharmonicity. Jortner and coworkers have extended the Marcus model to include quantum effects of ET rates by including the contributions of classical modes $\left(\mathrm{h} v \geq \mathrm{k}_{\mathrm{B}} \mathrm{T}\right)$ in the Frank-Condon (FC) factor represented by A. ${ }^{54}$ 


$$
A=\left(\frac{\pi}{\hbar^{2} E_{s} k_{B} T}\right)^{1 / 2} \exp \left(-\frac{1}{2} \sum_{i=1}^{N} \Delta^{2}{ }_{c i}\right)_{w_{1}=0} \sum \sum_{w_{2}=0} \ldots \ldots . . \sum_{w_{N}=0} \prod_{i=1}^{N} Q
$$

Where,

$$
Q={\frac{\left(\Delta^{2}{ }_{c i}\right.}{w_{i} !}}^{w_{i}} \exp \left(-\beta\left(\Delta E-E_{s}-\sum_{i=1}^{N} w_{i} \hbar \omega_{c i}\right)^{2} / 4 E_{s}\right.
$$

Here, $\mathrm{E}_{\mathrm{s}}, \Delta_{\mathrm{c}}, \Delta \mathrm{E}$ denotes solvent reorganization energy, the reduced potential surface displacements for the normal modes involved during the ET reaction, free energy of reaction for the ET process, respectively, and $\beta=\left(\mathrm{k}_{\mathrm{B}} \mathrm{T}\right)^{-1}$. All other terms carry their usual meanings. The vibrational energy $(\hbar \omega)$ is affected by the isotope effect and hence may give rise to KIE in ET rates. The model predicted both normal and inverse KIE depending upon the frequency shifts and the displaced potential energy surfaces of the reacting components.

Realizing that some of the thiols ( 30\%) stay protonated in these SAMs and are likely strongly $\mathrm{H}$-bonded to their neighbouring thiolates as indicated by a very weak -SH stretch at $2155 \mathrm{~cm}^{-1}$ relative to $2550 \mathrm{~cm}^{-1}$ in free thiols, the KIE observed here can originate from one of the many possible normal modes at the interface that may be displaced during ET. In particular, very large $\left(>200 \mathrm{~cm}^{-1}\right)$ normal $\mathrm{H} / \mathrm{D}$ isotope effects were observed for $\mathrm{C}-\mathrm{S}-\mathrm{H}$ bending modes and large inverse $\left(10-30 \mathrm{~cm}^{-1}\right) \mathrm{H} / \mathrm{D}$ isotope effects were observed on the C-S stretching modes (both Gauche and Trans). Observation of such strong coupling between these modes and very weak $\mathrm{S}-\mathrm{H}$ vibration suggests that the thiols at the interface are likely strongly hydrogen bonded to the neighbouring thiolates. It is conceivable that these modes change during electron transfer. Of course, this requires the ET from the electrode to be localized at these Au-SAM units. Such a proposal requires vetting from more sophisticated experiments and calculations.

Observation of normal KIE in $\mathrm{N}_{3} \mathrm{C}_{11} \mathrm{SH}-\mathrm{C}_{8} \mathrm{SH}$ and inverse KIE in $\mathrm{N}_{3} \mathrm{C}_{16} \mathrm{SH}-\mathrm{C}_{16} \mathrm{SH}$ necessarily entails the geometry of the interface to be different between these SAMs. Generally, the structure of Authiol interface is different for short chain and long chain alkyl thiol which reflects in their tilt angle and tilt direction with respect to the Au surface. ${ }^{55}$ It is conceivable that the vibrational modes that are involved in ET vary between different thiols. ${ }^{45}$ A plot of tilt angle and tilt direction of the SAM with the chain length shows that the structure of $\mathrm{Au}-\mathrm{RS}(\mathrm{H})$ interface varies substantially as the chain length is changed. (Fig. 6) The detailed effect of these structural changes on the vibration, though evident from the differences from the SERS data, is beyond the scope of current investigation and is non-trivial. The difference in the SAM structure can have the potential to direct an inverse KIE for the $\mathrm{N}_{3} \mathrm{C}_{16} \mathrm{SH} / \mathrm{D}-\mathrm{C}_{16} \mathrm{SH} / \mathrm{D}$ SAM with respect to the rest of the SAMs used in our study showing a normal isotope effect. Similarly, the fact that normal KIE is observed in $\mathrm{N}_{3} \mathrm{C}_{11} \mathrm{SH}-\mathrm{C}_{8} \mathrm{SH}$ SAM where there is through space tunneling and an inverse $\mathrm{KIE}$ is observed in $\mathrm{N}_{3} \mathrm{C}_{16} \mathrm{SH}-\mathrm{C}_{16} \mathrm{SH}$ where there is through bond tunneling may not be coincidental. Rather, those effects may result from differences in the SAM thiol interface. Only more definitive description of this SAM/Au interface can help to realize the origin of these ET properties.
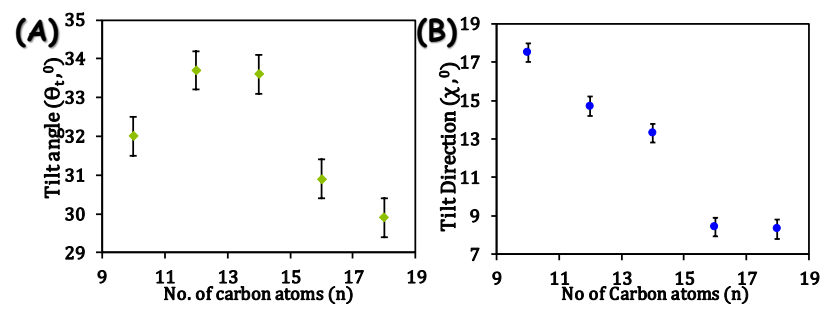

Fig.6: The dependence of tilt angle and tilt direction with respect to the chain length of the alkyl thiol SAM on Au. The values are taken from earlier reports. ${ }^{55}$

\section{Conclusion}

In conclusion, ET between Au-SAM electrode and a covalently attached Fc moiety shows thiol SH/SD isotope effect. Several AuSAM interfaces with varying chain length of the thiol are demonstrated to show KIE on ET rates. KIE is confirmed using both CA and Laviron's approach. In the case of $\mathrm{N}_{3} \mathrm{C}_{11} \mathrm{SH} / \mathrm{D}-\mathrm{C}_{8} \mathrm{SH} / \mathrm{D}$ modified $\mathrm{Au}$ electrode (substantial through space tunneling), a normal $\mathrm{KIE}$ on ET is seen which changes to an inverse in the case of $\mathrm{N}_{3} \mathrm{C}_{16} \mathrm{SH} / \mathrm{D}-\mathrm{C}_{16} \mathrm{SH} / \mathrm{D}$ SAM (substantial through bond tunneling). These observations compel invoking of quantum effect on ET from the vibrations originating from the $\mathrm{Au}-(\mathrm{H}) \mathrm{SR}$ interface which shift dramatically on H/D substitution. The results clearly suggest that further detailed investigation of these useful interfaces is required.

\section{ASSOCIATED CONTENT}

\section{Supporting Information}

The Supporting Information is available free of charge on the ACS Publication website.

Synthesis of linkers, their characterization, detailed experimental methods, additional electrochemical and SERS data (PDF)

\section{AUTHOR INFORMATION}

\section{Corresponding Author}

*icad@iacs.res.in

\section{Present Addresses}

School of Chemical Sciences, Indian Association for the Cultivation of Sciences, Jadavpur, Kolkata-700032.

\section{Author Contributions}

\$These authors contributed equally.

\section{ORCID}

Samir Chattopadhyay: 0000-0003-4759-0362

Abhishek Dey: 0000-0002-9166-3349

\section{Notes}

The Authors declare no competing financial interest.

\section{ACKNOWLEDGMENT}

The Research is funded by DST-SERB (EMR/2016/008063). S.C. deeply acknowledge IACS Integrated Ph.D. program.

\section{REFERENCES}

1. Robinson, D. B.; Chidsey, C. E. D., Submicrosecond Electron Transfer to Monolayer-Bound Redox Species on Gold Electrodes at Large Overpotentials. The Journal of Physical Chemistry B 2002, 106 (41), 10706-10713.

2. Gutierrez, A.; Paine, M.; Wolf, C. R.; Scrutton, N. S.; Roberts, G. C. K., Relaxation Kinetics of Cytochrome P450 Reductase: Internal Electron Transfer Is Limited by Conformational Change and Regulated by Coenzyme Binding. Biochemistry 2002, 41 (14), 4626-4637.

3. Schoenfisch, M. H.; Pemberton, J. E., Air Stability of Alkanethiol Self-Assembled Monolayers on Silver and Gold Surfaces. Journal of the American Chemical Society 1998, 120 (18), 4502-4513.

4. Sikes, H. D.; Smalley, J. F.; Dudek, S. P.; Cook, A. R.; Newton, M. D.; Chidsey, C. E. D.; Feldberg, S. W., Rapid Electron Tunneling 
Through Oligophenylenevinylene Bridges. Science 2001, 291 (5508), 1519.

5. Chi, Q.; Farver, O.; Ulstrup, J., Long-range protein electron transfer observed at the single-molecule level: In situ mapping of redox-gated tunneling resonance. Proceedings of the National Academy of Sciences of the United States of America 2005, 102 (45), 16203.

6. Ulman, A., Formation and Structure of Self-Assembled Monolayers. Chemical Reviews 1996, 96 (4), 1533-1554.

7. Wilson, E. K., DNA: INSULATOR OR WIRE? Chemical \& Engineering News Archive 1997, 75 (8), 33-39.

8. Murphy, C. J.; Arkin, M. R.; Jenkins, Y.; Ghatlia, N. D.; Bossmann, S. H.; Turro, N. J.; Barton, J. K., Long-range photoinduced electron transfer through a DNA helix. Science 1993, 262 (5136), 1025.

9. Arkin, M. R.; Stemp, E. D. A.; Holmlin, R. E.; Barton, J. K.; Hörmann, A.; Olson, E. J. C.; Barbara, P. F., Rates of DNAMediated Electron Transfer Between Metallointercalators. Science 1996, 273 (5274), 475.

10. Weber, K.; Hockett, L.; Creager, S., Long-Range Electronic Coupling between Ferrocene and Gold in Alkanethiolate-based Monolayers on Electrodes. The Journal of Physical Chemistry $B$ 1997, 101 (41), 8286-8291.

11. Liu, B.; Bard, A. J.; Mirkin, M. V.; Creager, S. E., Electron Transfer at Self-Assembled Monolayers Measured by Scanning Electrochemical Microscopy. Journal of the American Chemical Society 2004, 126 (5), 1485-1492.

12. Chidsey, C. E. D.; Bertozzi, C. R.; Putvinski, T. M.; Mujsce, A. M., Coadsorption of ferrocene-terminated and unsubstituted alkanethiols on gold: electroactive self-assembled monolayers. Journal of the American Chemical Society 1990, 112 (11), 4301 4306.

13. Chattopadhyay, S.; Sarkar, A.; Chatterjee, S.; Dey, A., Functional adlayers on Au electrodes: some recent applications in hydrogen evolution and oxygen reduction. Journal of Materials Chemistry A 2018, 6 (4), 1323-1339.

14. Smalley, J. F., Kinetics of interfacial ion-transfer reactions studied using the indirect laser-induced temperature jump technique: Theory. Journal of Electroanalytical Chemistry 2010, 640 (1), 68-74.

15. Smalley, J. F.; Newton, M. D.; Feldberg, S. W., An informative subtlety of itemperature-jump or coulostatic responses for surface-attached species. Electrochemistry Communications 2000, 2 (12), 832-838.

16. Smalley, J. F.; Finklea, H. O.; Chidsey, C. E. D.; Linford, M. R.; Creager, S. E.; Ferraris, J. P.; Chalfant, K.; Zawodzinsk, T.; Feldberg, S. W.; Newton, M. D., Heterogeneous ElectronTransfer Kinetics for Ruthenium and Ferrocene Redox Moieties through Alkanethiol Monolayers on Gold. Journal of the American Chemical Society 2003, 125 (7), 2004-2013.

17. Smalley, J. F.; Feldberg, S. W.; Chidsey, C. E. D.; Linford, M. R.; Newton, M. D.; Liu, Y.-P., The Kinetics of Electron Transfer Through Ferrocene-Terminated Alkanethiol Monolayers on Gold. The Journal of Physical Chemistry 1995, 99 (35), 1314113149.

18. Nuzzo, R. G.; Zegarski, B. R.; Dubois, L. H., Fundamental studies of the chemisorption of organosulfur compounds on gold(111). Implications for molecular self-assembly on gold surfaces. Journal of the American Chemical Society 1987, 109 (3), 733-740.

19. Lee, J.-G.; Lee, J.; Yates, J. T., Nondissociative Chemisorption of Methanethiol on $\mathrm{Ag}(110)$ : A Critical Result for SelfAssembled Monolayers. Journal of the American Chemical Society 2004, 126 (2), 440-441.

20. Rzeźnicka, I. I.; Lee, J.; Maksymovych, P.; Yates, J. T., Nondissociative Chemisorption of Short Chain Alkanethiols on
Au(111). The Journal of Physical Chemistry B 2005, 109 (33), 15992-15996.

21. Bryant, M. A.; Pemberton, J. E., Surface Raman scattering of self-assembled monolayers formed from 1-alkanethiols at silver [electrodes]. Journal of the American Chemical Society 1991, 113 (10), 3629-3637.

22. Bryant, M. A.; Pemberton, J. E., Surface Raman scattering of self-assembled monolayers formed from 1-alkanethiols: behavior of films at gold and comparison to films at silver. Journal of the American Chemical Society 1991, 113 (22), 82848293.

23.Tielens, F.; Santos, E., AuS and SH Bond Formation/Breaking during the Formation of Alkanethiol SAMs on Au(111): A Theoretical Study. The Journal of Physical Chemistry C 2010, 114 (20), 9444-9452.

24. Szafranski, C. A.; Tanner, W.; Laibinis, P. E.; Garrell, R. L., Surface-Enhanced Raman Spectroscopy of Aromatic Thiols and Disulfides on Gold Electrodes. Langmuir 1998, 14 (13), 35703579.

25. Heaven, M. W.; Dass, A.; White, P. S.; Holt, K. M.; Murray, R. W., Crystal Structure of the Gold Nanoparticle $\left[\mathrm{N}\left(\mathrm{C}_{8} \mathrm{H}_{17}\right)_{4}\right]\left[\mathrm{Au}_{25}\left(\mathrm{SCH}_{2} \mathrm{CH}_{2} \mathrm{Ph}\right)_{18}\right]$. Journal of the American Chemical Society 2008, 130 (12), 3754-3755.

26. Jadzinsky, P. D.; Calero, G.; Ackerson, C. J.; Bushnell, D. A.; Kornberg, R. D., Structure of a Thiol Monolayer-Protected Gold Nanoparticle at $1.1 \AA$ Resolution. Science 2007, 318 (5849), 430.

27. Pei, Y.; Gao, Y.; Shao, N.; Zeng, X. C., Thiolate-Protected $\mathrm{Au}_{20}(\mathrm{SR})_{16}$ Cluster: Prolate Au8 Core with New [Au3(SR)4] Staple Motif. Journal of the American Chemical Society 2009, 131 (38), 13619-13621.

28. Matthiesen, J. E.; Jose, D.; Sorensen, C. M.; Klabunde, K. J., Loss of Hydrogen upon Exposure of Thiol to Gold Clusters at Low Temperature. Journal of the American Chemical Society 2012, 134 (22), 9376-9379.

29. Kankate, L.; Turchanin, A.; Gölzhäuser, A., On the Release of Hydrogen from the S-H groups in the Formation of SelfAssembled Monolayers of Thiols. Langmuir 2009, 25 (18), 10435-10438.

30. Petroski, J.; Chou, M.; Creutz, C., The coordination chemistry of gold surfaces: Formation and far-infrared spectra of alkanethiolate-capped gold nanoparticles. Journal of Organometallic Chemistry 2009, 694 (7), 1138-1143.

31. Reimers, J. R.; Ford, M. J.; Halder, A.; Ulstrup, J.; Hush, N. S., Gold surfaces and nanoparticles are protected by $\mathrm{Au}(0)$-thiyl species and are destroyed when $\mathrm{Au}(\mathrm{I})$-thiolates form. Proceedings of the National Academy of Sciences 2016, 113 (11), E1424.

32. Reimers, J. R.; Ford, M. J.; Marcuccio, S. M.; Ulstrup, J.; Hush, N. S., Competition of van der Waals and chemical forces on gold-sulfur surfaces and nanoparticles. Nature Reviews Chemistry 2017, 1, 0017.

33. Li, T. T. T.; Weaver, M. J., Intramolecular electron transfer at metal surfaces. 4. Dependence of tunneling probability upon donor-acceptor separation distance. Journal of the American Chemical Society 1984, 106 (20), 6107-6108.

34. Chi, Q.; Zhang, J.; Andersen, J. E. T.; Ulstrup, J., Ordered Assembly and Controlled Electron Transfer of the Blue Copper Protein Azurin at Gold (111) Single-Crystal Substrates. The Journal of Physical Chemistry B 2001, 105 (20), 4669-4679.

35. Vassilian, A.; Wishart, J. F.; Van Hemelryck, B.; Schwarz, H.; Isied, S. S., Electron transfer across polypeptides. 6. Long-range electron transfer in osmium-ruthenium binuclear complexes bridged with oligoproline peptides. Journal of the American Chemical Society 1990, 112 (20), 7278-7286.

36. Isied, S. S.; Vassilian, A.; Wishart, J. F.; Creutz, C.; Schwarz, H. A.; Sutin, N., The distance dependence of intramolecular 
electron-transfer rates: importance of the nuclear factor. Journal of the American Chemical Society 1988, 110 (2), 635637.

37. Closs, G. L.; Calcaterra, L. T.; Green, N. J.; Penfield, K. W.; Miller, J. R., Distance, stereoelectronic effects, and the Marcus inverted region in intramolecular electron transfer in organic radical anions. The Journal of Physical Chemistry 1986, 90 (16), 3673-3683.

38. Closs, G. L.; Miller, J. R., Intramolecular Long-Distance Electron Transfer in Organic Molecules. Science 1988, 240 (4851), 440.

39. Avila, A.; Gregory, B. W.; Niki, K.; Cotton, T. M., An Electrochemical Approach to Investigate Gated Electron Transfer Using a Physiological Model System: Cytochrome c Immobilized on Carboxylic Acid-Terminated Alkanethiol SelfAssembled Monolayers on Gold Electrodes. The Journal of Physical Chemistry B 2000, 104 (12), 2759-2766.

40. Collman, J. P.; Devaraj, N. K.; Decréau, R. A.; Yang, Y.; Yan, Y.L.; Ebina, W.; Eberspacher, T. A.; Chidsey, C. E. D., A Cytochrome c Oxidase Model Catalyzes Oxygen to Water Reduction Under Rate-Limiting Electron Flux. Science 2007, 315 (5818), 1565.

41. Bhunia, S.; Rana, A.; Roy, P.; Martin, D. J.; Pegis, M. L.; Roy, B.; Dey, A., Rational Design of Mononuclear Iron Porphyrins for Facile and Selective $4 \mathrm{e}^{-} / 4 \mathrm{H}^{+} \mathrm{O}_{2}$ Reduction: Activation of $\mathrm{O}-\mathrm{O}$ Bond by 2nd Sphere Hydrogen Bonding. Journal of the American Chemical Society 2018, 140 (30), 9444-9457.

42. Mukherjee, M.; Dey, A., Electron Transfer Control of Reductase versus Monooxygenase: Catalytic $\mathrm{C}-\mathrm{H}$ Bond Hydroxylation and Alkene Epoxidation by Molecular Oxygen. ACS Central Science 2019.

43. Zhou, J.-G.; Hagelberg, F., Do Methanethiol Adsorbates on the Au(111) Surface Dissociate? Physical Review Letters 2006, 97 (4), 045505.

44. Grönbeck, H.; Curioni, A.; Andreoni, W., Thiols and Disulfides on the Au(111) Surface: The Headgroup-Gold Interaction. Journal of the American Chemical Society 2000, 122 (16), 3839-3842.

45. Bandyopadhyay, S.; Chattopadhyay, S.; Dey, A., The protonation state of thiols in self-assembled monolayers on roughened $\mathrm{Ag} / \mathrm{Au}$ surfaces and nanoparticles. Physical Chemistry Chemical Physics 2015, 17 (38), 24866-24873.

46. Zubrägel, C.; Deuper, C.; Schneider, F.; Neumann, M.; Grunze, M.; Schertel, A.; Wöll, C., The presence of two different sulfur species in self-assembled films of n-alkanethiols on $\mathrm{Au}$ and Ag surfaces. Chemical Physics Letters 1995, 238 (4), 308312.

47. Chidsey, C. E. D., Free Energy and Temperature Dependence of Electron Transfer at the Metal-Electrolyte Interface. Science 1991, 251 (4996), 919.

48. Forster, R. J.; Faulkner, L. R., Electrochemistry of Spontaneously Adsorbed Monolayers. Equilibrium Properties and Fundamental Electron Transfer Characteristics. Journal of the American Chemical Society 1994, 116 (12), 5444-5452.

49. Mukherjee, S.; Bandyopadhyay, S.; Dey, A., Tuning the apparent formal potential of covalently attached ferrocene using SAM bearing ionizable $\mathrm{COOH}$ groups. Electrochimica Acta 2013, 108, 624-633.

50. Devaraj, N. K.; Decreau, R. A.; Ebina, W.; Collman, J. P.; Chidsey, C. E. D., Rate of Interfacial Electron Transfer through the 1,2,3-Triazole Linkage. The Journal of Physical Chemistry $B$ 2006, 110 (32), 15955-15962.

51. Laviron, E., General expression of the linear potential sweep voltammogram in the case of diffusionless electrochemical systems. Journal of Electroanalytical Chemistry and Interfacial Electrochemistry 1979, 101 (1), 19-28.
52. Eckermann, A. L.; Feld, D. J.; Shaw, J. A.; Meade, T. J., Electrochemistry of redox-active self-assembled monolayers. Coordination Chemistry Reviews 2010, 254 (15), 1769-1802.

53. Finklea, H. O.; Hanshew, D. D., Electron-transfer kinetics in organized thiol monolayers with attached pentaammine(pyridine)ruthenium redox centers. Journal of the American Chemical Society 1992, 114 (9), 3173-3181.

54. Ulstrup, J.; Jortner, J., The effect of intramolecular quantum modes on free energy relationships for electron transfer reactions. The Journal of Chemical Physics 1975, 63 (10), 43584368.

55. Fenter, P.; Eberhardt, A.; Liang, K. S.; Eisenberger, P., Epitaxy and chainlength dependent strain in self-assembled monolayers. The Journal of Chemical Physics 1997, 106 (4), 1600-1608.

TOC

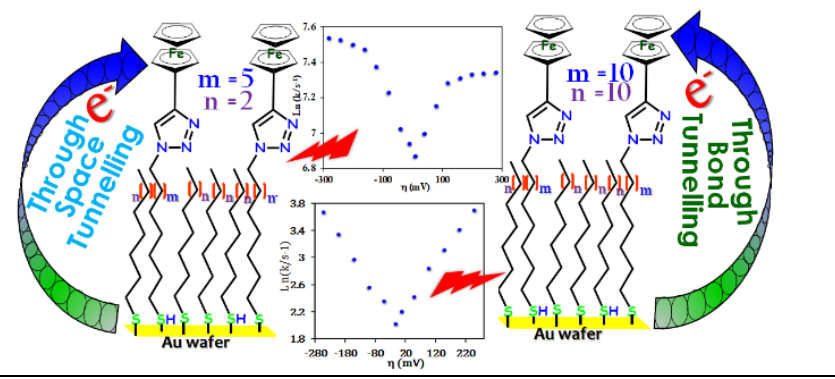

